\author{
Military Technical College \\ Kobry El-Kobbah, \\ Cairo, Egypt.
}

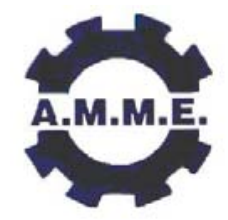
$13^{\text {th }}$ International Conference on Applied Mechanics and Mechanical Engineering.

\title{
FINITE ELEMENT MODEL OF A SMART ISOTROPIC BEAM WITH DISTRIBUTED PIZOELECETRIC ACTUATORS
}

\author{
BENDARY* I.M., EI-SHAFEI* M. A. and RIAD* A.M.
}

\begin{abstract}
In this paper, the static and dynamic loading of an intelligent beam structure with distributed piezoelectric actuators has been studied. The structure substrate, made of isotropic material, subjected to axial and transverse mechanical loads as well as electrical load. The actuators layers are made of piezoelectric material of PZT type. The one-dimensional isoperimetric Hermit cubic shape functions and the Lagrange interpolation function are used to formulate the finite element model for the distributed coupled electromechanical behavior. The equation of motion of the structure systems is obtained by using the principle of total potential energy considering the Euler-Bernoulli beam assumptions. The results of the proposed finite element model are compared to the available finite element and analytical results of other investigators, good agreement is generally obtained.
\end{abstract}

\section{KEY WORDS}

Finite element - Piezoelectric materials - Composite structure - Smart structure system - Adaptive structure.

\section{NOMENCLATURE}

\section{Symbols}

$\begin{array}{ll}m_{e} & \text { Mass matrix of the beam element in stretching. } \\ \ddot{q} & \text { Second derivative of the nodal displacement. } \\ k_{e} & \text { Beam Element stiffness matrix. } \\ \mathrm{F}_{\mathrm{e}} & \text { Beam Element nodal forces. } \\ \Pi & \text { Total potential energy. } \\ \mathrm{U} & \text { Internal strain energy. } \\ \mathrm{V} & \text { External potential energy. } \\ \mathrm{W} & \text { Work due to external applied load. }\end{array}$

* Egyptian Armed Forces. 


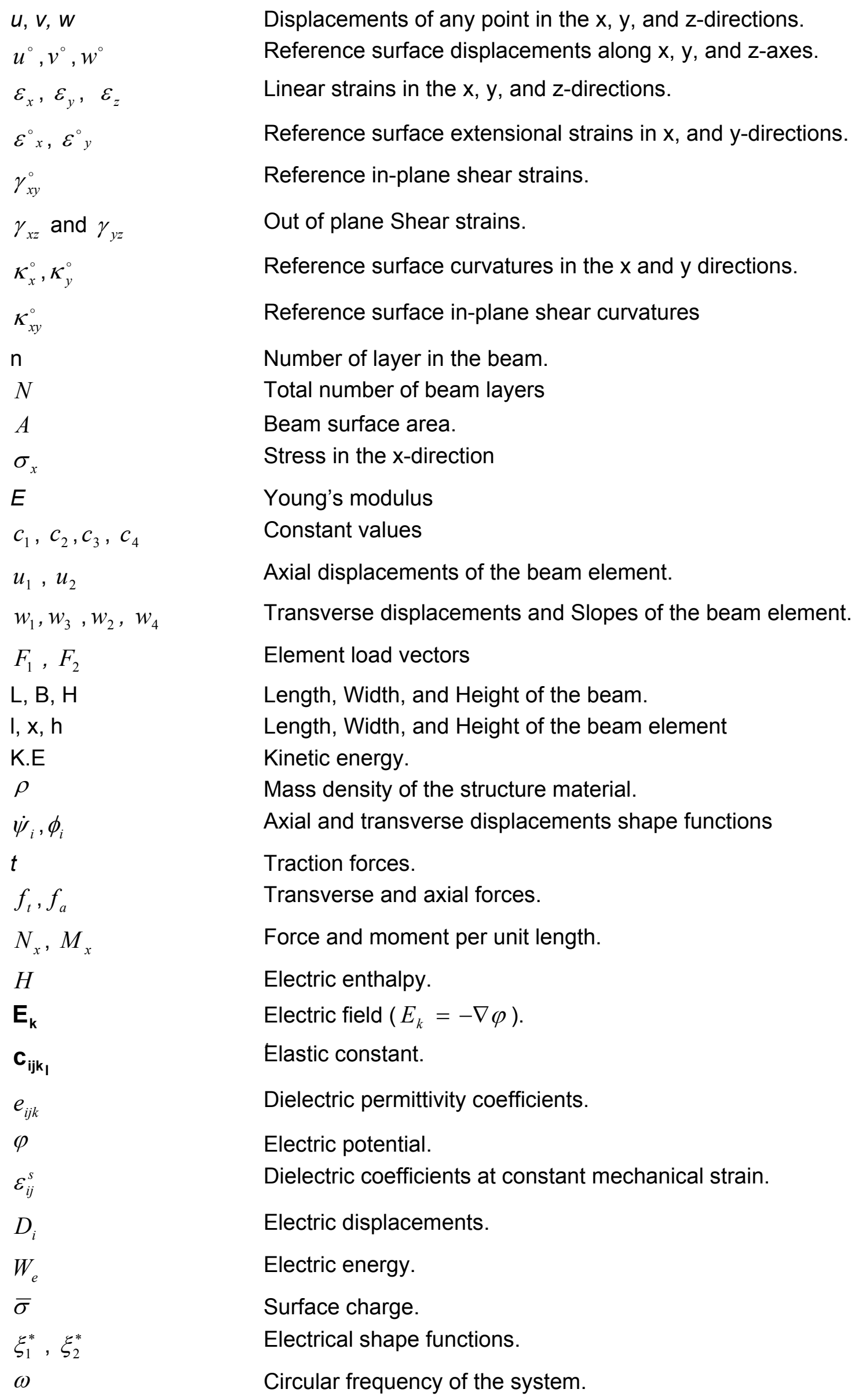




\section{INTRODUCTION}

The integration of the distributed actuators with the structure is currently used as an active control on its elastic deformation. The distributed actuators and sensors are mad of piezoelectric materials. These materials induce electric potential/charge when it is subjected to mechanical deformations by virtue of direct piezoelectric effect and deformed under the externally applied voltage by virtue of converse piezoelectric effect.

Henno and Huges [1] used tetrahedral piezoelectric elements for vibration analysis. They introduced the concept of "static condensation of the electric potential degrees of freedom", which presents the electric potential and loads written in terms of the mechanical properties of the structure. Their study was considered as a reference for electro-elastic finite element derivations for plates, shells, and axi-symmetric solids. Crawley and Lazarus [2] studied theoretically and experimentally the induced strain actuation of plate components of an intelligent structure. Their work leads to understand the system design parameters and to model the structure systems. Good agreement between their measured and predicted deformations was found and their results demonstrated that the induced strain actuation was effective for controlling the structure deformation.

Hagood et al. [3] modeled the effect of dynamic coupling between a structure and an electrical network considering the piezoelectric effect. They developed three models, the first concerned with the direct voltage driven electrodes, the second was for direct charge driven electrodes, whereas the third was for the indirect driven case. Their measurements gave good agreement with the corresponding predicted results. Robbins and Reddy [4], and Reddy [5] studied the static and dynamic interaction between bonded piezoelectric actuators and an underlying beam substructure using four different displacement-based finite element models. Their four models, two for single-layer and two for multi-layer, were based on two-dimensional beam theory and did not include the strain energy of the piezoelectric materials in the potential energy integral. Therefore, they did not regard the piezoelectric materials as part of the structure. The predicted results of their models showed that: (i) similar transverse displacements, and (ii) similar static stress fields except near the end of the actuator. In addition, both multi-layer models gave large transverse stresses near the end of the actuator and smooth continuous functions of the thickness coordinate, despite abrupt changes in material properties from one layer to another. The predicted frequency amplitudes using the classical bending theory model were differed significantly from the corresponding amplitudes of other models; whereas the predicted amplitudes by the layer-wise models were differ significantly from those of the single-layer models.

Yang and Ngoi [6] investigated analytically the shape control of beams with piezoelectric actuators. They derived the analytical solution of a beam deflection induced by both piezoelectric and external forces. Their predicted results showed that it was difficult to approach the desired shape of a beam locally with piezoelectric actuators. Strambi et al. [7] discussed the relationship between the pin-force and EulerBernoulli models, especially for the case of one side actuation layer. Their obtained solution showed how the system was excited by a combined bending-compressive actuation, and how the actuator induced a combined flexural-extensional deformation. Bhattacharya et al. [8] found that the application of electrical voltages and boundary conditions produced significant changes in the free vibration frequencies. They also showed that: (i) the cantilever beam had frequencies significantly higher than simply 
supported or clamped beams subjected to actuating voltages, and (ii) the effect of inplane stress on the overall stiffness was high compared to the bending stress with the application of electric loading.

In the present work, a simple finite element model has been proposed to describe the behavior of an advanced smart beam when subjected to axial and transverse loads in addition to electrical load. A hermit cubic shape function is used to formulate the finite element model. The equation of motion is obtained based on the energy principle. The results of the present model are compared with the corresponding predictions of other investigators.

\section{FINITE ELEMENT MODEL}

\section{Strain-Displacement Relations}

The displacement field equations for the cantilever beam can be represented by [9]:

$$
\begin{aligned}
u(x, y, z) & =u^{\circ}(x, y)-z \frac{\partial w^{\circ}(x, y)}{\partial x}, \\
v(x, y, z) & =v^{\circ}(x, y)-z \frac{\partial w^{\circ}(x, y)}{\partial y}, \text { and } \\
w(x, y, z) & =w^{\circ}(x, y) .
\end{aligned}
$$

The strain-displacement relationships can be obtained by differentiating the displacement-field equations as follow [9]:

$$
\begin{aligned}
& \varepsilon_{x}(x, y, z) \equiv \frac{\partial u(x, y, z)}{\partial x}=\frac{\partial u^{\circ}(x, y)}{\partial x}-z \frac{\partial^{2} w^{\circ}(x, y)}{\partial x^{2}}=\varepsilon_{x}^{\circ}+z \kappa_{x}^{\circ}, \\
& \varepsilon_{y}(x, y, z) \equiv \frac{\partial v(x, y, z)}{\partial y}=\frac{\partial v^{\circ}(x, y)}{\partial y}-z \frac{\partial^{2} w^{\circ}(x, y)}{\partial y^{2}}=\varepsilon_{y}^{\circ}+z \kappa_{y}^{\circ}, \\
& \varepsilon_{z}(x, y, z) \equiv \frac{\partial w(x, y, z)}{\partial z}=\frac{\partial w^{\circ}(x, y)}{\partial z}, \\
& \gamma_{x y}(x, y, z) \equiv \frac{\partial v(x, y, z)}{\partial x}+\frac{\partial u(x, y, z)}{\partial y}=\gamma_{x y}^{\circ}+z \kappa_{x y}^{\circ}, \\
& \gamma_{x z}(x, y, z) \equiv \frac{\partial w(x, y, z)}{\partial x}+\frac{\partial u(x, y, z)}{\partial z}, \text { and } \\
& \gamma_{y z}(x, y, z) \equiv \frac{\partial w(x, y, z)}{\partial y}+\frac{\partial v(x, y, z)}{\partial z} .
\end{aligned}
$$

For the case of the beam length is too long in comparison with the other two dimensions both $\varepsilon_{y}$ and $\gamma_{x y}$ are assumed equal to zero [10]. According to Kirchhoff's hypothesis, the strain components $\varepsilon_{z}, \gamma_{x z}$, and $\gamma_{y z}$ are vanish. By applying these assumptions on Eqn. (4), the axial strain can be written as: 
$\varepsilon_{x}(x, y, z)=\varepsilon_{x}^{\circ}+z \kappa_{x}^{\circ}$.

By using a Hooks' law, the normal stress can be expressed as:

$$
\sigma_{x x}=E \varepsilon_{x x}
$$

\section{Piezoelectric Constitutive Relations}

The amount of energy stored in the material can be described by the electric enthalpy, $H$, where the term $H$ is analogous to enthalpy in the thermodynamics. The electric enthalpy of the piezoelectric material is expressed by [11]:

$$
H=\frac{1}{2} c_{i j k l} \varepsilon_{i j} \varepsilon_{k l}-e_{i j k} E_{i} \varepsilon_{j k}-\frac{1}{2} \varepsilon^{s}{ }_{i j} E_{i} E_{j} .
$$

The constitutive equations of the piezoelectric element are obtained by differentiating the enthalpy with respect to the strain. These equations are represented by [11, 19]:

$$
\begin{aligned}
& \sigma_{i j}=\frac{\partial H}{\partial \varepsilon_{i j}} \\
& \sigma_{i j}=c_{i j k l} \varepsilon_{k l}-e_{i j k} E_{k} .
\end{aligned}
$$

The differentiation of the electric enthalpy with respect to the electric field $E_{k}$ defines the piezoelectric electric displacement as:

$$
\begin{aligned}
& D_{i}=-\frac{\partial H}{\partial E_{i}} \\
& D_{i}=e_{i k l} \varepsilon_{k l}+\varepsilon^{s}{ }_{i k} E_{k} .
\end{aligned}
$$

Finally, the piezoelectric constitutive equations can be written in a matrix form as:

$$
\left\{\begin{array}{c}
\sigma_{i j} \\
D_{i}
\end{array}\right\}=\left[\begin{array}{cc}
c_{i j k l} & -e_{i j k} \\
e_{i j k} & \varepsilon_{i k}^{s}
\end{array}\right]\left\{\begin{array}{c}
\varepsilon_{k l} \\
E_{k}
\end{array}\right\} .
$$

The electric field components are related to the electrostatic potential $\varphi$ by the equation:

$$
E_{k}=-\varphi_{, k}=-\frac{\partial \varphi}{\partial z}
$$

\section{Variational Formulation}

The equation of motion of the structure system is derived herein using the principle of minimum potential energy. The total energy of the structure system is represented by [3]: 


$$
\Pi=U-W_{e}+W .
$$

The internal strain energy is represented by [2]:

$$
U=\int_{v} \frac{1}{2} \varepsilon_{k l} \sigma_{i j} d v
$$

For an electromechanical medium, the internal strain energy for the structure system $V$ is the sum of internal strain energy, Eqn. (15), and the electric energy, Eqn. (7), i.e.

$$
V=-\int_{v} \frac{1}{2} c_{i j k l} \varepsilon_{i j} \varepsilon_{k l}-e_{i j k} E_{i} \varepsilon_{j k}-\frac{1}{2} \varepsilon_{i j}^{s} E_{i} E_{j} d v \text {. }
$$

The work done due to the external load is defined as [12]:

$$
W=\iint_{R}\left[t u_{j}+f_{t} w-\sigma \varphi\right] d x d y+\iint_{R}\left[f_{a} u\right] d y d z
$$

The work done due to external load represents the sum of the works done by surface tractions force $\mathrm{t}$, transverse force $f_{t}$, and axial forces $f_{a}$, respectively. After adding the flux of the electric energy, the resultant work done in the outward direction across the surface is represented by:

$$
W=\iint_{R}\left[t\left(u-z \frac{d w}{d x}\right)+f_{t} w-\sigma \varphi\right] d x d y+\iint_{R}\left[f_{a} u\right] d y d z
$$

Applying the principle of minimum potential energy and equating the first variation of the total potential energy $\Pi$ to zero results in:

$$
\delta \Pi=\delta(V-W)=0
$$

i.e.

$$
\delta V=\delta W
$$

Substituting by Eqns. (16) and (17)a into Eqn. (19) yields:

$$
\begin{aligned}
& \delta \int_{v}\left[-\frac{1}{2} c_{i j k l} \varepsilon_{i j} \varepsilon_{k l}+e_{i j k} E_{i} \varepsilon_{j k}+\frac{1}{2} \varepsilon_{i j}^{s} E_{i} E_{j}\right] d v \\
& =\delta \int_{s}\left[t u_{j}+f_{t} w-\bar{\sigma} \varphi\right] d s+\int_{s} f_{a} u d s
\end{aligned}
$$

Substituting by Eqns. (4) and (13) into Eqn. (16), the total internal strain energy of the structure is represented by:

$$
V=-\int_{v}\left[\frac{1}{2} c_{i j k l}\left(\frac{\partial u^{0}}{\partial x}-z \frac{\partial^{2} w^{0}}{\partial x^{2}}\right)^{2}-e_{i j k}\left(-\frac{\partial \varphi}{\partial z}\right)\left(\frac{\partial u^{0}}{\partial x}-z \frac{\partial^{2} w^{0}}{\partial x^{2}}\right)-\frac{1}{2} \varepsilon^{s}{ }_{i j}\left(-\frac{\partial \varphi}{\partial z}\right)^{2}\right] d v
$$


In order to minimize the total strain energy, the first variation is taken with respect to the axial and transverse displacements as well as the electric potentials. Thus, the first variations are represented by:

$$
\begin{aligned}
& \delta V=\int_{v}-c_{i j k l}\left(\frac{\partial u^{0}}{\partial x}\right)\left(\delta \frac{\partial u^{0}}{\partial x}\right) d v+\int_{v} c_{i j k l} z\left(\left(\delta \frac{\partial u^{0}}{\partial x}\right)\left(\frac{\partial^{2} w^{0}}{\partial x^{2}}\right)+\left(\frac{\partial u^{0}}{\partial x}\right)\left(\delta \frac{\partial^{2} w^{0}}{\partial x^{2}}\right)\right) d v \\
& +\int_{v} c_{i j k l} z^{2}\left(\frac{\partial^{2} w^{0}}{\partial x^{2}}\right)\left(\delta \frac{\partial^{2} w^{0}}{\partial x^{2}}\right) d v-\int_{v} e_{i j k}\left(\frac{\partial \varphi}{\partial z}\right)\left(\delta \frac{\partial u^{0}}{\partial x}\right) d v-\int_{v} e_{i j k} z\left(\frac{\partial \varphi}{\partial z}\right)\left(\delta \frac{\partial^{2} w^{0}}{\partial x^{2}}\right) d v \\
& -\int_{v} \varepsilon_{i j}^{s}\left(\frac{\partial \varphi}{\partial z}\right)\left(\delta \frac{\partial \varphi}{\partial z}\right) d v
\end{aligned}
$$

and

$$
\delta W=\iint_{R} t \delta u d x d y-\iint_{R} z t \frac{d w}{d x} \delta w d x d y+\iint_{R} f_{t} \delta w d x d y-\sigma \varphi \delta \varphi d x d y+\iint_{R} f_{a} \delta u d y d z
$$

The mass matrix can be obtained using the kinetic energy which is given by:

$$
T=\iiint_{V}^{1} \frac{1}{2}\left[\begin{array}{ll}
\dot{u} & \dot{w}
\end{array}\right]^{2} \rho d V .
$$

\section{FINITE ELEMENT FORMULATION}

The displacement of a beam subjected to axial stretching is given by [13]:

$$
\frac{\partial^{2} u}{\partial x^{2}}=0
$$

The solution of the above governing equation is:

$$
u(x)=c_{1}+c_{2} x=\left[\begin{array}{ll}
1 & x
\end{array}\right]\left[\begin{array}{l}
c_{1} \\
c_{2}
\end{array}\right] .
$$

Upon imposing the nodal boundary conditions in Eqn. (26) and determining the constants values $c_{1}$ and $c_{2}$, the displacement equation is rewritten as:

$$
u(x)=\left[\begin{array}{ll}
1 & x
\end{array}\right]\left[\begin{array}{ll}
1 & 0 \\
-\frac{1}{\mathrm{~L}} & \frac{1}{L}
\end{array}\right]\left\{\begin{array}{l}
u_{1} \\
u_{2}
\end{array}\right\},
$$

which can be expressed as; 


$$
u(x)=u_{1} \psi_{1}+u_{2} \psi_{2}=\sum_{j=1}^{2} u_{j} \psi_{j}
$$

where the shape functions are;

$$
\psi_{1}=1-\frac{x}{L}, \quad \psi_{2}=\frac{x}{L}
$$

The shape functions can be expressed in a matrix form for the beam element as:

$$
\left[N_{a}\right]=\left\{\psi_{1}, \psi_{2}\right\}=\left[\begin{array}{ll}
1 & x
\end{array}\right]\left[\begin{array}{cc}
1 & 0 \\
-\frac{1}{L} & \frac{1}{L}
\end{array}\right]=\left\{1-\frac{x}{L}, \frac{x}{L}\right\} .
$$

The governing equation for a beam under bending is [4]:

$$
\frac{\partial^{4} w}{\partial x^{4}}=0
$$

Solving the above equation and imposing the nodal boundary conditions yields:

$$
w(x)=w_{1} \phi_{1}+w_{2} \phi_{2}+w_{3} \phi_{3}+w_{4} \phi_{4}=\sum_{j=1}^{4} w_{j} \phi_{j},
$$

The shape functions take the form:

$$
\begin{aligned}
\phi_{1} & =1-3\left(\frac{x}{L}\right)^{2}+2\left(\frac{x}{L}\right)^{3}, & \phi_{2} & =-x\left(1-\frac{x}{L}\right)^{2}, \\
\phi_{3} & =3\left(\frac{x}{L}\right)^{2}-2\left(\frac{x}{L}\right)^{3}, & \phi_{4} & =-x\left[\left(\frac{x}{L}\right)^{2}-\frac{x}{L}\right] .
\end{aligned}
$$

The vector form of the shape functions is represented by:

$$
\left[N_{b}\right]=\left\{\phi_{1}, \phi_{2}, \phi_{3}, \phi_{4}\right\}
$$

For the piezoelectric element, the electric field is treated as the electric degrees of freedom like a generalized displacement degrees of freedom. Thus, each node has four degrees of freedom, three mechanical degrees of freedom and one electric degree of freedom. The governing equation for the electric potential is given by [14]:

$$
-\nabla^{2} \varphi=0 \text {. }
$$

By solving Eqn. (35) and applying the boundary condition, the electric potential takes the form: 


$$
\varphi(z)=\varphi_{1} \xi_{1}^{*}+\varphi_{2} \xi_{2}^{*}=\sum_{j=1}^{2} \varphi_{j} \xi_{j}^{*}
$$

where the electric shape functions $\xi_{1}^{*}$ and $\xi_{2}^{*}$ are derived and represented by:

$$
\xi_{1}^{*}=\frac{1}{2}+\frac{z}{h} \quad ; \quad \xi_{2}^{*}=\frac{1}{2}-\frac{z}{h}
$$

The electric potentials at the boundary are arbitrary unless specified or varied along the length of the beam. In the present work, the electric potential is considered to be a function of the thickness and the length of the beam. Therefore, the electric shape function at the nodal element, represented by the product of the axial displacement shape function, Eqn. (29), into the thickness shape function, Eqn. (36), has the following form:

$$
N_{e}=\left\{1-\frac{x}{l}, \frac{x}{l}\right\}\left\{\frac{1}{2}+\frac{z}{h}, \frac{1}{2}-\frac{z}{h}\right\} .
$$

Homogenous boundary conditions for the electric potentials will be imposed on the bottom surface to eliminate rigid body modes. So, the shape functions are finally take the form [15]:

$$
\begin{gathered}
N_{e}=\left\{1-\frac{x}{l}, \frac{x}{l}\right\}\left\{\frac{1}{2}+\frac{z}{h}\right\}, \\
N_{e}=\left\{\xi_{1}, \xi_{2}\right\},
\end{gathered}
$$

where

$$
\xi_{1}=\left(\frac{1}{2}+\frac{z}{h}\right)\left(1-\frac{x}{l}\right) ; \xi_{2}=\left(\frac{1}{2}+\frac{z}{h}\right)\left(\frac{x}{l}\right) .
$$

Substituting by the shape functions, Eqns. (29), (33), and (40) into Eqns. (22), (23), and (24), the first variation of strain energy and virtual work has the following form:

$$
\begin{aligned}
& \delta V=\int_{v}\left[c_{i j k l}\left(\frac{\partial \psi_{j}}{\partial x} \frac{\partial \psi_{i}}{\partial x}\right) u_{i}-c_{i j k l} z\left(\frac{\partial \psi_{j}}{\partial x} \frac{\partial^{2} \phi_{i}}{\partial x^{2}}\right) w_{i}+e_{i j k}\left(\frac{\partial \psi_{j}}{\partial x} \frac{\partial \xi_{i}}{\partial z}\right) \varphi_{i}\right] \delta u_{i} d v \\
& -\int_{v}\left[c_{i j k l} z\left(\frac{\partial^{2} \phi_{j}}{\partial x^{2}} \frac{\partial \psi_{i}}{\partial x}\right) u_{i}-c_{i j k l} z^{2}\left(\frac{\partial^{2} \phi_{j}}{\partial x^{2}} \frac{\partial^{2} \phi_{i}}{\partial x^{2}}\right) w_{i}+e_{i j k} z\left(\frac{\partial^{2} \phi_{j}}{\partial x^{2}} \frac{\partial \xi_{i}}{\partial z}\right) \varphi_{i}\right] \delta w_{i} d v \\
& +\int_{v}\left[c_{i j k l}\left(\frac{\partial \xi_{j}}{\partial z} \frac{\partial \psi_{i}}{\partial x}\right) u_{i}-c_{i j k l} z\left(\frac{\partial \xi_{j}}{\partial z} \frac{\partial^{2} \phi_{i}}{\partial x^{2}}\right) w_{i}-\varepsilon_{i j}^{s}\left(\frac{\partial \xi_{j}}{\partial z} \frac{\partial \xi_{i}}{\partial z}\right) \varphi_{i}\right] \delta \varphi_{i} d v
\end{aligned}
$$

and 


$$
\begin{aligned}
& \delta W=\iint_{R}\left[\psi_{j} t\right] \delta u_{i} d x d y+\iint_{R}\left[\psi_{j} f_{a}\right] \delta u_{i} d y d z \\
& -\iint_{R}\left[\xi_{j} \sigma\right] \delta \varphi_{i} d x d y+\iint_{R}\left[\phi_{j} f_{t}-z \frac{d \phi_{j}}{d x} t\right] \delta w_{i} d x d y
\end{aligned}
$$

Equation (42) can be expressed as:

$$
\begin{aligned}
& F_{1}=\iint_{R}\left[\psi_{j} t\right] d x d y+\iint_{R}\left[\psi_{j} f_{a}\right] d y d z \\
& F_{2}=\iint_{R}\left[\phi_{j} f_{t}-z \frac{d \phi_{j}}{d x} t\right] d x d y \\
& F_{3}=-\iint_{R}\left[\xi_{j} \sigma\right] d x d y .
\end{aligned}
$$

Equation (24) can be rewritten as:

$$
T=\frac{1}{2}\left[\dot{u}_{1} \dot{u}_{2} \dot{w}_{1} \dot{w}_{2} \dot{w}_{3} \dot{w}_{4}\right] \rho A \int\left[\begin{array}{c}
\psi_{1} \\
\psi_{2} \\
\phi_{1} \\
\phi_{2} \\
\phi_{3} \\
\phi_{4}
\end{array}\right]\left[\psi_{1} \psi_{2} \phi_{1} \phi_{2} \phi_{3} \phi_{4}\right] d x\left[\begin{array}{c}
\dot{u}_{1} \\
\dot{u}_{2} \\
\dot{w}_{1} \\
\dot{w}_{2} \\
\dot{w}_{3} \\
\dot{w}_{4}
\end{array}\right] .
$$

\section{EQUATION OF MOTION}

From Eqn. (41), the element stiffness matrices are:

$$
\begin{aligned}
& \mathrm{K}_{11}=\iint_{A} E\left(\frac{d \psi_{j}}{d x} \frac{d \psi_{i}}{d x}\right) \mathrm{d} \mathrm{x} \mathrm{dy}, \\
& \mathrm{K}_{12}=-\iint_{A} E \frac{d \psi_{i}}{d x} \frac{d^{2} \phi_{J}}{d x^{2}} \mathrm{dx} \mathrm{dy}, \\
& \mathrm{K}_{13}=\iint_{V} \int_{13} \frac{d \psi_{j}}{d x} \frac{d \xi_{i}}{d z} \mathrm{dx} \mathrm{dy} \mathrm{dz}, \\
& \mathrm{K}_{21}=-\iint_{A} E \frac{d^{2} \phi_{j}}{d x^{2}} \frac{d \psi_{i}}{d x} \mathrm{dx} \mathrm{dy}, \\
& \mathrm{K}_{22}=\iint_{A} E \frac{d^{2} \phi_{j}}{d x^{2}} \frac{d^{2} \phi_{i}}{d x^{2}} \mathrm{dx} \mathrm{dy}, \\
& \mathrm{K}_{23}=-\iint_{V} \int e_{13} z \frac{d^{2} \phi_{j}}{d x^{2}} \frac{d \xi_{i}}{d z} \mathrm{dx} \mathrm{dy} \mathrm{dz}, \\
& \mathrm{K}_{31}=\iint_{V} \int e_{13} \frac{d \xi_{j}}{d z} \frac{d \psi_{i}}{d x} \mathrm{dx} \mathrm{dy} \mathrm{dz}, \\
& \mathrm{K}_{32}=-\iint_{V} \int e_{13} z \frac{d \xi_{j}}{d z} \frac{d^{2} \phi_{i}}{d x^{2}} \mathrm{dx} \mathrm{dy} \mathrm{dz},
\end{aligned}
$$


and

$$
\mathrm{K}_{33}=-\iint_{V} \int \varepsilon_{33}^{s} \frac{d \xi_{j}}{d z} \frac{d \xi_{i}}{d z} \mathrm{dx} \mathrm{dy} \mathrm{dz}
$$

Substituting by Eqns. (29), (33) and (40) into Eqns. (43)a to (43)c and (44)a to (44)i, and by Eqns. (29) and (33) into Eqn. (44), then and perform the integration for a beam element with length $L$, width $b$ and height $h$, the element stiffness matrix, the element load vector and the element mass matrix can be expressed by:

$$
\begin{aligned}
k_{e}= & {\left[\begin{array}{lll}
K_{11} & K_{12} & K_{13} \\
K_{21} & K_{22} & K_{23} \\
K_{31} & K_{32} & K_{33}
\end{array}\right], } \\
& F_{e}=\left[\begin{array}{lll}
F_{1} & F_{2} & F_{3}
\end{array}\right],
\end{aligned}
$$

The static equilibrium equation for the structure system can be obtained as:

$$
\left[\begin{array}{lll}
K_{11} & K_{12} & K_{13} \\
K_{21} & K_{22} & K_{23} \\
K_{31} & K_{32} & K_{33}
\end{array}\right]\left\{\begin{array}{l}
u \\
w \\
\varphi
\end{array}\right\}=\left\{\begin{array}{l}
F_{1} \\
F_{2} \\
F_{3}
\end{array}\right\},
$$

where

$$
\begin{array}{ll}
K_{u u}=\left[\begin{array}{ll}
K_{11} & K_{12} \\
K_{21} & K_{22}
\end{array}\right] ; & K_{u \varphi}=\left[\begin{array}{l}
K_{13} \\
K_{23}
\end{array}\right] \\
K_{\varphi u}=\left[\begin{array}{ll}
K_{31} & K_{32}
\end{array}\right] ; & K_{\varphi \varphi}=\left[K_{33}\right] .
\end{array}
$$

Thus, the equation of motion of the whole structure systems is represented by:

$$
\left[\begin{array}{cc}
M_{u u} & 0 \\
0 & 0
\end{array}\right]\left\{\begin{array}{l}
\{\ddot{U}\} \\
\{\ddot{\varphi}\}
\end{array}\right\}+\left[\begin{array}{ll}
{\left[K_{u u}\right]} & {\left[K_{u \varphi}\right]} \\
{\left[K_{\varphi u}\right]} & {\left[K_{\varphi \varphi}\right]}
\end{array}\right]\left\{\begin{array}{l}
\{U\} \\
\{\varphi\}
\end{array}\right\}=\left\{\begin{array}{l}
\{F\} \\
\{Q\}
\end{array}\right\},
$$

where $M_{u u}$ is the global mass matrix of the structure and $\{U\}=\{\{u\},\{w\}\}$ is the global nodal generalized displacement coordinates, $\{\varphi\}$ is the global nodal generalized electric coordinates vector describing the applied voltage at the actuators [16], $\{F\}$ is the applied mechanical load vector, and $\{Q\}$ is the electric excitation vector. The global mass matrix, stiffness matrix and applied mechanical vector could be shown in Appendix A.

The introduced model is converted to a computer program. The input data to the program are beam dimensions, adhesive layer and piezoelectric patch data, material properties of the structure system, numbers of elements and applied mechanical and/or electrical forces. The model predictions are concerned with axial and transverse displacements, respectively, and free natural frequency of the structure system. A validation of model results will be presented. 


\section{VALIDATION OF MODEL RESULTS}

In the following, the behavior of a laminated aluminum beam with a piezoelectric actuator is investigated using the interactive MATLAB code. The properties for the aluminum beam, adhesive layer, and piezoelectric layer (PZT-4) are listed in Table 1 [10]. Figure 1 shows the predicted transverse deflection of the aluminum beam subjected to a concentrated load of $10(\mathrm{~N})$ at its free end as function of beam length. The corresponding predictions obtained by Ref. [10] are depicted on the same figure. Good agreement is generally obtained between the results obtained from the present model with that of Ref. [10].

Table. 1. Material data of aluminum Beam with piezoelectric actuator.

\begin{tabular}{|c|c|c|c|}
\hline Data & $\begin{array}{c}\text { Aluminum } \\
\text { beam }\end{array}$ & Adhesive & $\begin{array}{c}\text { PZT-4 } \\
\text { actuator }\end{array}$ \\
\hline$E_{11},[\mathrm{MPa}]$ & 68.9 & 6.9 & 83 \\
\hline$E_{33},[\mathrm{MPa}]$ & 68.9 & 6.9 & 66 \\
\hline$\gamma_{13}$ & 0.25 & 0.4 & 0.31 \\
\hline$G_{13},[\mathrm{MPa}]$ & 27.6 & 2.46 & 31 \\
\hline$d_{31},[\mathrm{~m} / \mathrm{v}]$ & 0 & 0 & $-122 * 10^{-12}$ \\
\hline$d_{33},[\mathrm{~m} / \mathrm{v}]$ & 0 & 0 & $285 * 10^{-12}$ \\
\hline$\varepsilon_{31}^{s},[\mathrm{farad} / \mathrm{m}]$ & 0 & 0 & 0 \\
\hline$\varepsilon_{33}^{s},[\mathrm{farad} / \mathrm{m}]$ & 0 & 0 & $11.53 * 10^{-9}$ \\
\hline$\rho,\left[\mathrm{kg} / \mathrm{m}^{3}\right]$ & 2769 & 1662 & 7600 \\
\hline $\mathrm{L},[\mathrm{m}]$ & 0.1524 & 0.1524 & 0.1524 \\
\hline $\mathrm{H},[\mathrm{m}]$ & 0.01524 & 0.000254 & 0.001524 \\
\hline $\mathrm{B},[\mathrm{m}]$ & 0.0254 & 0.0254 & 0.0254 \\
\hline
\end{tabular}

For a beam with piezoelectric layer completely covered the surface, the electrical load described by a constant electric field of $12.5 \mathrm{kv}$ was applied on the upper surface of the piezoelectric layer, while the lower surface was grounded ( 0 Volt). A concentrated mechanical load of $10(N)$ was applied in some cases and had zero values for the other cases. The results obtained are compared with that of Refs. [17-18]. Figure 2 shows that the results of the proposed model are close to that obtained by Refs. [17-18]. These results assess the predictive capabilities of the proposed model.

The influence of number of elements and discrete layers on middle plane displacement has been predicted using the proposed model. Table 2 lists the results obtained for the axial and transverse displacements for different number of elements compared to the results obtained by Ref. [17]. The current predicted transverse displacement of aluminum beam is better than that predicted for longitudinal displacement. 


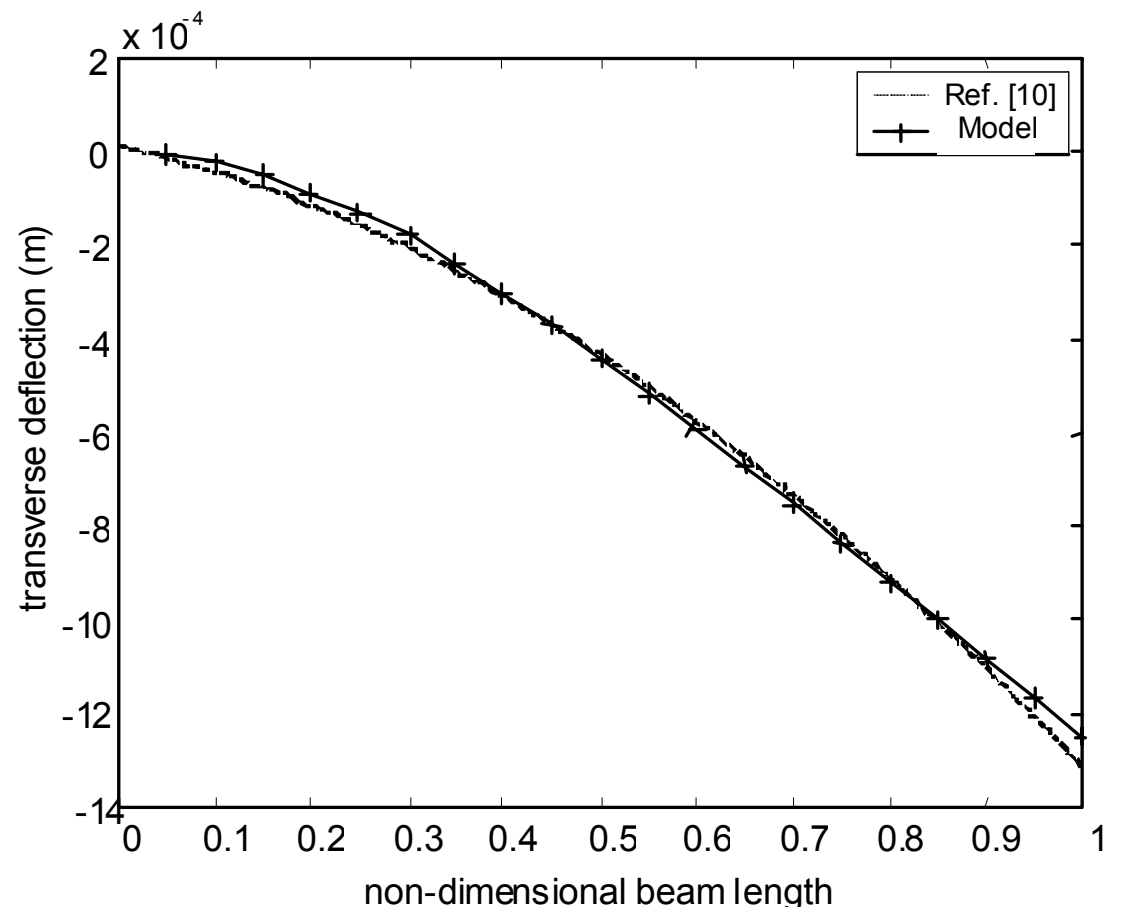

Fig. 1. The change of the transverse deflection along the aluminum beam length, compared with Ref. [10].

Table 3 lists the free dynamic predictions of the fundamental natural frequencies of the aluminum beam when the applied voltage on the upper surface of the PZT-4 is equal to zero. The predicted natural frequencies by the present model are compared with that obtained by Refs. [4,17]; a good agreement is generally obtained. The maximum difference between the predicted natural frequency by the present model and that predicted by Ref. [4] was found to be $1.4 \%$.

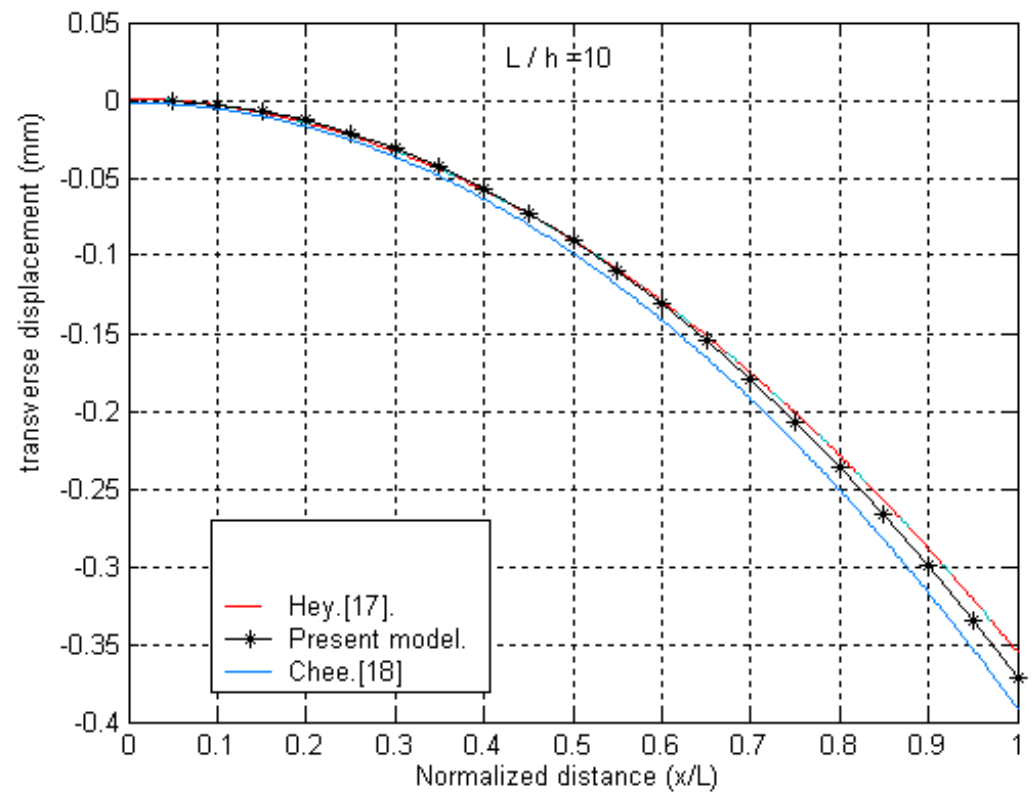

Fig. 2. Predicted transverse deflection of Aluminum beam with piezoelectric actuators compared with Ref. [17,18]. 
Table. 2. Effect of the number of elements and discrete layers on middle plane tip displacement of the beam.

\begin{tabular}{|c|c|c|c|c|c|}
\hline \multicolumn{2}{|c|}{$\begin{array}{c}\text { Normalized } \\
\text { displacement }\end{array}$} & $\begin{array}{c}\text { No. of } \\
\text { elements }\end{array}$ & $\begin{array}{c}\text { Discrete } \\
\text { layers }\end{array}$ & $\begin{array}{c}\text { Hey[17] } \\
\text { Alum. }\end{array}$ & $\begin{array}{c}\text { Current } \\
\text { Model } \\
\text { Alum. }\end{array}$ \\
\hline $\begin{array}{c}\text { Axial } \\
\text { displacement }\end{array}$ & $\mathrm{u}(10000) / \mathrm{h}$ & 10 & $6 / 2 / 2$ & 7.832 & 9.184 \\
& 20 & $6 / 2 / 2$ & 7.812 & 9.325 \\
\hline $\begin{array}{c}\text { Transverse } \\
\text { displacement }\end{array}$ & $\mathrm{W}(100) / \mathrm{h}$ & 25 & $6 / 2 / 2$ & 7.813 & 9.348 \\
\hline & 20 & $6 / 2 / 2$ & -2.026 & -2.118 \\
& 25 & $6 / 2 / 2$ & -2.022 & -2.182 \\
\hline
\end{tabular}

Table. 3. Predicted natural frequencies of aluminum beam with single PZT-4 layer.

\begin{tabular}{|c|c|c|c|}
\hline $\begin{array}{c}\text { No. of } \\
\text { elements }\end{array}$ & $\begin{array}{c}\text { Natural } \\
\text { Frequency [4] }\end{array}$ & $\begin{array}{c}\text { Natural } \\
\text { Frequency [17] }\end{array}$ & $\begin{array}{c}\text { Current } \\
\text { model }\end{array}$ \\
\hline 10 & 539.3 & 539.7 & 530.9 \\
20 & 538.6 & 539.3 & 530.9 \\
30 & 538.5 & 539.1 & 530.8 \\
\hline
\end{tabular}

Figures (3) and (4) show the effect of applied voltages on transverse and axial displacements of aluminum beam with the piezoelectric actuator, respectively. It is seen from both figures that the transverse and axial displacements increases with increasing the applied voltage.

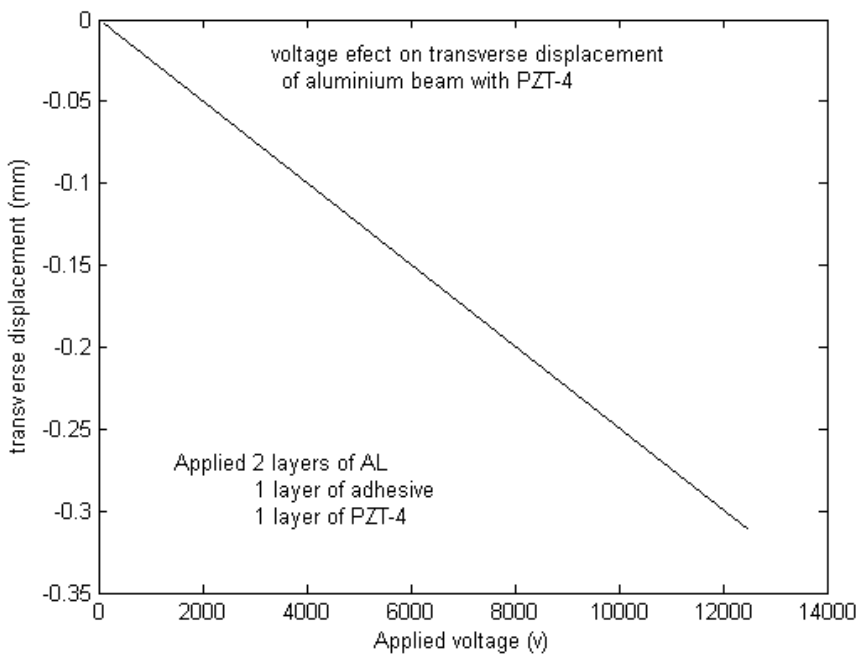

Fig. 3. The influence of the applied voltage on the transverse displacement of aluminum beam with piezoelectric actuator. 


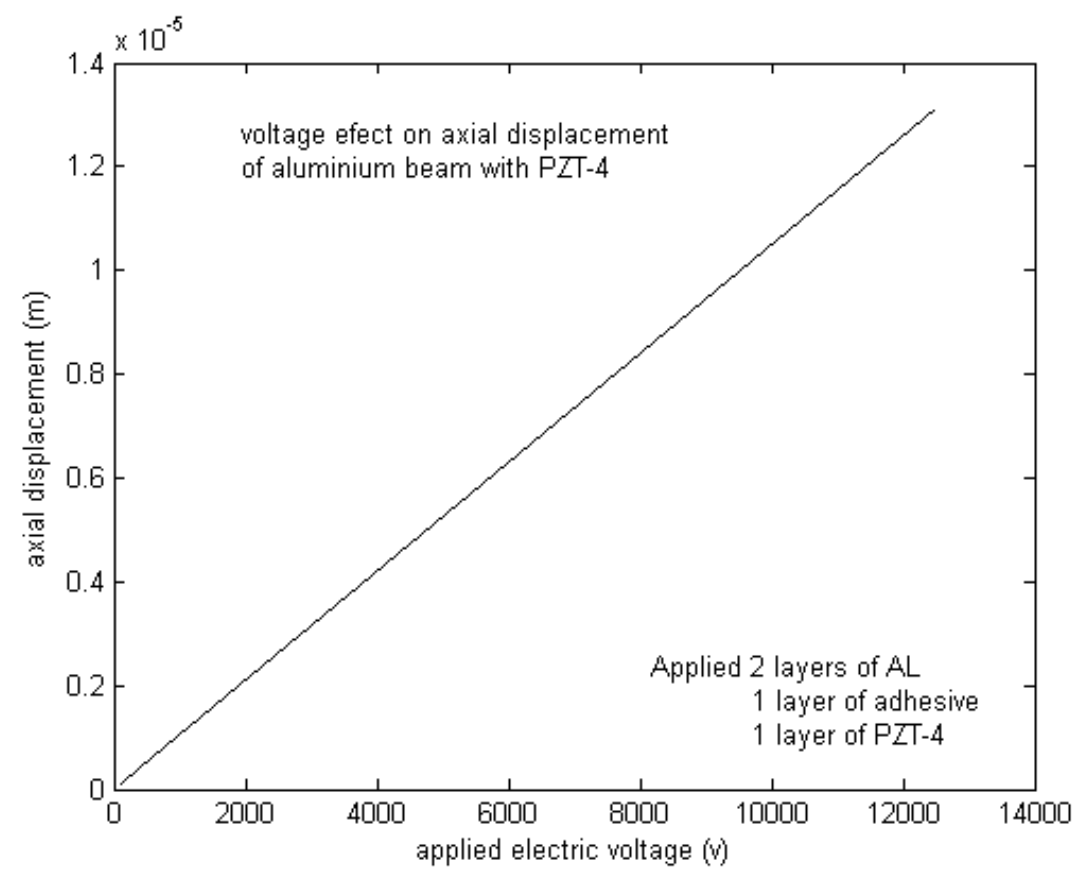

Fig. 4. The influence of the applied voltage on the axial displacement of aluminum beam with piezoelectric actuator.

\section{CONCLUSIONS}

A finite element model has been proposed to predict the static and free dynamic characteristics of a laminated beam with distributed piezoelectric actuators. The following conclusions have been drawn:

1. The good agreement between the model predictions and the corresponding predicted results of other investigators proves the predictive capabilities of such model.

2. The finite element model results were found to converge towards an asymptote at resizable number of elements.

3. As the applied voltage increases, both the transverse and axial displacements increase, respectively.

4. As the number of layers increases, the transverse deflection decreases.

5. The inclusion of shear correction factor in the present model may improve its predictions.

6. The model can be extended to characterize a fiber reinforced composite structures with smart materials.

\section{REFERENCES}

[1] Henno, A.\& Huges, T. J.R., "Finite Element Method for Piezoelectric Vibration", Int. J. for Numerical Methods in Engineering, Vol. 2, pp. 151-157 (1970).

[2] Crawley, E.F. and Lazarus, K.B., "Induced Strain Actuation of Isotropic and Anisotropic Plates” AIAA journal Vol. 29, No. 6, pp. 944-951 (1991). 
[3] Hagood, N.W., Chung, W.H.\& Florow, A.V. "Modeling of Piezoelectric Actuator Dynamics for Active Structural Control", J. of Int. Mater. Syst. \& Struct., Vol. 1 (1990).

[4] Robbins, D.H. \& Reddy, J.N., "Analysis of Piezoelectrically Actuated Beams Using A Layer-Wise Displacement Theory", Computers \& Structures, Vol. 41, No.2, pp. 265-279 (1991).

[5] Reddy, J.N. "A Generalization Of Two-Dimensional Theories Of Laminated Composite Plates", Comp. Appl. Numer. Meth., Vol. 3, No. 173 (1987).

[6] Yang, S. and Ngoi, B., "Shape Control of Beams by Piezoelectric Actuators" AIAA Journal, Vol. 38 No. 12 ( 2000).

[7] Strambi G., Barboni, R \&Gaudenzi, P., "Pin-Force And Euler - Bernoulli Models For Analysis Of Intelligent Structures" AIAA J. Vol. 33, No. 9, pp.1746-1749 (1995).

[8] Bhattacharya, P., Suhail, H., and Sinha, P.K., "Finite Element Free Vibration Analysis of Smart Laminated Composite Beams and Plates", comp. \& struct, Vol.(3), No. 16 (1998).

[9] Allin, D.H. and Hasiler, W.E., "Int. to Aerospace Structural Analysis", John Willy \&Sons, Inc. (1985).

[10] Logan, D.L., "A First Course in the Finite Element Method", PWS-KENT (1992).

[11] Khdeir, A.A.\& Reddy, J.N., "An Exact Solution for the Bending of Thin and Thick Cross-Ply Laminated Beams", Comp\&Struct., Vol. 37, pp.195-203,1997.

[12] Rao, S.R. and Ganesan, N., "Dynamic Response of Non-Uniform Composites Beam", Journal of Sound and Vibration, pp. 563-577 (1997).

[13] Yildirm V., Sancaktar, E. and Kiral, E., " Comparison Of The In-Plane Natural Frequencies of Symmetric Cross-Ply Laminated Beams Based on The BernoulliEurler and Timoshenko Beam Theories", Journal of Applied Mechanics, Vol. 66, pp. 410-417 (1999).

[14] Giavotto V., Borri M., Mantegazza P., Ghiringhelli G., Carmashi V. Maffioli G. and Mussi F., "Anisotropic Beam Theory And Applications", Comp. \& Struct., Vol. 16, No. 4, pp. 403-413 (1983).

[15] Hagodes D., Atilgan A., Fulton M.\&Rehfield L., "Free Vibration Analysis of Composite Beams", J.of Amer. Helic. Society, Vol.36, No.3, pp. 36-47, (1991).

[16] Elshafei, M.A., "Smart Composite Plate Shape Control Using Piezoelectric Materials"; Ph.D. Dissertation, US Naval postgraduate school, sep (1996).

[17] D.A. Saravanos \& P.R. Heyliger, "Coupled Layerwise Analysis of Composite Beams with Embedded Piezoelectric Sensors and Actuators," J.of Intelligent Material Systems and Structures, Vol. 6- May 1995.

[18] Clinton Y.K. Chee, Liyong Tong and Grant P. Steven" A mixed Model for Composite Beams with Piezoelectric Actuators And Sensors," Smart Mater. Struct. Vol. 8, 1999, pp. 417-432.

[19] David H. Allen, Walter E. Haisler, "Introduction to Aerospace Structural Analysis", John Wiley \& Sons, 1985. 


\section{Appendix A:}

$$
\begin{aligned}
& k_{e}=E\left[\begin{array}{cccccccc}
\frac{b}{L} & -\frac{b}{L} & 0 & -\frac{b}{L} & 0 & \frac{b}{L} & -\frac{e_{31} b}{2} & \frac{e_{31} b}{2} \\
-\frac{b}{L} & \frac{b}{L} & 0 & \frac{b}{L} & 0 & -\frac{b}{L} & -\frac{e_{31} b}{2} & \frac{e_{31} b}{2} \\
0 & 0 & \frac{12 b}{L^{3}} & \frac{6 b}{L^{2}} & -\frac{12 b}{L^{3}} & \frac{6 b}{L^{2}} & \frac{e_{31} b h}{4 L} & -\frac{e_{31} b h}{2 L} \\
-\frac{b}{L} & \frac{b}{L} & \frac{6 b}{L^{2}} & \frac{4 b}{L} & -\frac{6 b}{L^{2}} & \frac{2 b}{L} & \frac{e_{31} b h}{4 L} & 0 \\
0 & 0 & -\frac{12 b}{L^{3}} & -\frac{6 b}{L^{2}} & \frac{12 b}{L^{3}} & -\frac{6 b}{L^{2}} & -\frac{e_{31} b h}{4 L} & \frac{e_{31} b h}{4 L} \\
\frac{b}{L} & -\frac{b}{L} & \frac{6 b}{L^{2}} & \frac{2 b}{L} & -\frac{6 b}{L^{2}} & \frac{4 b}{L} & 0 & 0 \\
-\frac{e_{31} b}{2} & -\frac{e_{31} b}{2} & \frac{e_{31} b h}{4 L} & \frac{e_{31} b h}{4 L} & -\frac{e_{31} b h}{4 L} & 0 & -\frac{\varepsilon_{33}^{s} b L}{3 h} & -\frac{\varepsilon_{33}^{s} b L}{6 h} \\
\frac{e_{31} b}{2} & \frac{e_{31} b}{2} & -\frac{e_{31} b h}{2 L} & 0 & \frac{e_{31} b h}{4 L} & 0 & -\frac{\varepsilon_{33}^{s} b L}{6 h} & -\frac{\varepsilon_{33}^{s} b L}{3 h}
\end{array}\right] \\
& {\left[m_{e}\right]=\frac{\rho A L}{420}\left[\begin{array}{cccccc}
140 & 147 & 21 L & 70 & 63 & -14 L \\
147 & 156 & 22 L & 63 & 54 & -13 L \\
21 L & 22 L & 4 L^{2} & 14 L & 13 L & -3 L^{2} \\
70 & 63 & 14 L & 140 & 147 & -21 L \\
63 & 54 & 13 L & 147 & 156 & -22 L \\
-14 L & -13 L & -3 L^{2} & -21 L & -22 L & 4 L^{2}
\end{array}\right]} \\
& F_{1}=\left[\begin{array}{c}
\frac{t b L}{2}+f_{a}\left(1-\frac{x}{L}\right) b h \\
\frac{t b L}{2}+f_{a}\left(\frac{x}{L}\right) b h
\end{array}\right] \\
& F_{2}=\left[\begin{array}{c}
\frac{f_{t} b L}{2}+z b t \\
\frac{f_{t} b L^{2}}{12} \\
\frac{f_{t} b L}{2}-z b t \\
-\frac{f_{t} b L^{2}}{12}
\end{array}\right] F_{3}=\left[\begin{array}{c}
-\frac{3}{4} \frac{L b v \varepsilon_{33}^{s}}{h_{p}} \\
-\frac{3}{4} \frac{L b v \varepsilon_{33}^{s}}{h_{p}}
\end{array}\right] F_{e}=\left[\begin{array}{ll}
F & Q
\end{array}\right]=\left[\begin{array}{c}
\frac{t b L}{2}+f_{a}\left(1-\frac{x}{L}\right) b h \\
\frac{t b L}{2}+f_{a}\left(\frac{x}{L}\right) b h \\
\frac{f_{t} b L}{2}+z b t \\
\frac{f_{t} b L^{2}}{12} \\
\frac{f_{t} b L}{2}-z b t \\
-\frac{f_{t} b L^{2}}{12} \\
-\frac{3}{4} \frac{L b v \varepsilon_{33}^{s}}{h_{p}} \\
-\frac{3}{4} \frac{L b v \varepsilon_{33}^{s}}{h_{p}}
\end{array}\right]
\end{aligned}
$$

